\title{
A population-based study examining the effect of tyrosine kinase inhibitors on survival in metastatic renal cell carcinoma in Alberta and the role of nephrectomy prior to treatment
}

\author{
Mark Warren, MBBS, FRACP; ${ }^{*}$ Peter M. Venner, MD, FRCPC; ${ }^{\dagger}$ Scott North, MD, FRCPC, MHPE; ${ }^{*}$ \\ Tina Cheng, MD, MSc, FRCPC; ${ }^{\xi}$ Chris Venner, BSc, MD; ${ }^{\ddagger}$ Sunita Ghosh, PhD, PStat; ${ }^{*}$ Allison A. Venner, BSc; $;$ \\ Daygen Finch, MD, FRCPC
}

See related article on page 292

\section{Abstract}

Background: We performed a retrospective population-based study to assess the impact of tyrosine kinase inhibitors (TKIs) on overall survival (OS) in patients treated for metastatic renal cell carcinoma ( $m R C C)$ in Alberta, Canada and to assess the impact of nephrectomy on OS in patients treated with TKIs.

Methods: We identified 134 patients who began taking a TKI between December 2003 and June 2007 for mRCC in Alberta. We compared survival in this group to that in an earlier cohort of 141 patients treated with interferon- $\alpha$ (IFN- $\alpha$ ) between May 1995 and March 2003. We used the Kaplan-Meier method to determine OS, and we used a Cox proportional hazards model to determine hazard ratios (HRs) and confidence intervals (Cls). We performed multivariate analysis to assess the impact of neprhectomy on OS. Results: Of the 134 patients treated with TKIs, 81 received treatment in the first-line setting, whereas 53 received treatment after prior IFN- $\alpha$ therapy. All 141 patients from the IFN- $\alpha$ cohort received treatment in the first-line setting. Patients treated with TKIs had an improved OS compared with the IFN- $\alpha$ cohort $(\mathrm{HR} 0.61,95 \% \mathrm{Cl}$ $0.45-0.83, p=0.001)$. The median OS was 18 months in the TKI group and 10 months in the IFN- $\alpha$ group. The benefit of TKIs was confined to favourable and intermediate risk groups according to the Memorial Sloan-Kettering Cancer Center prognostic model. Prior nephrectomy was associated with improved OS in the TKI cohort, independent of other prognostic factors.

Conclusion: Tyrosine kinase inhibitors improve OS compared with IFN- $\alpha$ in mRCC. In patients treated with TKIs, prior nephrectomy is associated with improved survival independent of other prognostic variables.

Can Urol Assoc J 2009;3(4):281-9

\section{Résumé}

Contexte : Une étude rétrospective de population a été menée afin d'évaluer l'effet des inhibiteurs de la tyrosine-kinase (ITK) sur la survie globale (SG) des patients atteints d'un néphrocarcinome métastatique et d'évaluer l'impact d'une néphrectomie sur la SG des patients traités par ITK.

Méthodes : Cent trente-quatre patients en Alberta ont entrepris un traitement par ITK entre decembre 2003 et juin 2007 en raison d'un néphrocarcinome. On a comparé les taux de survie dans ce groupe avec ceux d'un groupe de 141 patients ayant entrepris un traitement de première intention par IFN- $\alpha$ entre mai 1995 et mars 2003. La survie globale a été calculée à l'aide de la méthode de Kaplan Meier, et le risque relatif (RR) et les intervalles de confiance (IC) ont été calculés à l'aide du modèle des risques proportionnels de Cox. Une analyse multivariée a permis d'évaluer l'impact de la néphrectomie sur la SG dans la population globale de l'étude d'une part et chez les patients traités par ITK d'autre part.

Résulfats : Les 134 patients ayant entrepris un traitement par ITK ont été répartis ainsi : traitement de première intention, 81 patients, et traitement de seconde intention après un traitement par IFN- $\alpha$, 53 patients. Les patients traités par ITK ont montré une SG supérieure par rapport aux patients traités par IFN- $\alpha$ (RR 0,61, IC à $95 \%$ 0,45$0,83, p=0,001)$. La SG médiane était de 18 mois chez les patients traités par ITK et de 10 mois chez les patients traités par IFN- $\alpha$. Le traitement par ITK n'a eu un avantage que chez les patients atteints de néphrocarcinome métastatique présentant un risque faible ou intermédiaire selon le modèle du Memorial Sloan-Kettering Cancer Cener. Une néphrectomie antérieure a été associée à une meilleure SG dans la cohorte traitée par ITK, indépendamment des autres facteurs pronostics.

Conclusion : Le traitement par ITK a amélioré la SG par rapport au traitement par IFN- $\alpha$ dans une population « réelle ». Une néphrectomie antérieure a été associée à une SG supérieure chez les patients traités par ITK.

\section{Introduction}

In Canada, the lifetime risk of cancer of the kidney is $1.8 \%$, with most of these cancers attributable to renal cell carcinoma. ${ }^{1}$ Although nephrectomy in early-stage disease is potentially curative, many patients will relapse and 39\% will 
ultimately die from the disease. Until recently, the mainstay of systemic treatment for metastatic renal cell carcinoma (mRCC) has been with immunotherapeutic agents such as interferon- $\alpha$ (IFN- $\alpha$ ) and high-dose interleukin-2 (IL-2); however, benefits have been modest and the median survival of patients treated with immunotherapy is still only 13 months. ${ }^{2}$ In patients with metastatic disease at the time of initial diagnosis, cytoreductive nephrectomy before the commencement of IFN- $\alpha$ has been shown to improve survival in prospective studies ${ }^{3-5}$ and has been offered to patients for whom surgery is suitable. This benefit may be independent of IFN- $\alpha$, given that response to IFN- $\alpha$ was not improved by a prior nephrectomy. ${ }^{6}$

In 2 recently reported clinical trials, ${ }^{7,8}$ tyrosine kinase inhibitors (TKIs) have demonstrated improvements in progression-free survival in first- and second-line treatment settings. In both studies, crossover and poststudy treatment with TKIs obscured the true magnitude of benefit of these agents on survival. In a recent update of the study comparing first-line sunitinib to IFN- $\alpha$, median overall survival (OS) was improved by 4.6 months with sunitinib, and this benefit increased to 14 months when censoring patients who received poststudy treatment. ${ }^{9}$ The role of cytoreductive nephrectomy before the commencement of therapy with TKIs in patients who present with metastatic disease has not yet been established in prospective studies. In the study by Motzer and colleagues, $90 \%$ of patients had undergone a prior nephrectomy.

The purpose of our study was to evaluate the impact of TKIs on survival in a "real-world setting" in patients with mRCC in Alberta, Canada. We also aimed to evaluate the impact of nephrectomy on OS in patients treated with TKIs.

\section{Methods}

\section{Background}

Alberta has a population of about 3.5 million. ${ }^{10}$ Most cancer patients in the province are treated at tertiary cancer centres in Edmonton (Cross Cancer Institute) and Calgary (Tom Baker Cancer (entre). Prior to the availability of TKIs, IFN- $\alpha$ was the main treatment administered for mRCC. Tyrosine kinase inhibitors (sunitinib and sorafenib) first became available in Alberta in late 2003, initially through 2 phase-III trials and subsequently through expanded access and compassionate release programs.

\section{Study design}

We performed a retrospective chart review of patients with
mRCC treated at either of the 2 major cancer centres in Alberta. We compared survival in a cohort of patients treated with TKIs to an earlier cohort treated with IFN- $\alpha$.

The IFN- $\alpha$ cohort consisted of patients with mRCC who received treatment between 1996 and 2003 (at a dose of $5-10 \times 10^{6}$ units subcutaneously 3 times/w). We identified eligible patients by combining a search of a Cancer registry database of patients in whom a diagnosis of invasive kidney cancer (excluding transitional cell carcinoma) had been made in Alberta with a database of attendance at either of the 2 major cancer centres. Although we defined no specific exclusion criteria with respect to parameters of organ function or performance status, it was uncommon for IFN- $\alpha$ to be offered to patients with poor performance status (ECOG status $\geq 3$ ) or with major organ dysfunction as tolerance would usually be poor in this clinical setting. We measured survival from the commencement of IFN- $\alpha$, and we collected baseline prognostic information at the commencement of treatment. All patients were treated in a first-line setting. This group formed a "historic" control with survival data being updated to May 2008 (group A).

The TKI cohort consisted of patients with mRCC who received either sorafenib or sunitinib between November 2003 and June 2007 at standard dosages and schedules. We identified patients using similar methods to those used for the IFN- $\alpha$ group, with additional patients identified through pharmacy records, clinical research records and individual physician records. Inclusion and exclusion criteria were defined by the program through which each patient obtained their TKIs.

For the primary analysis, we divided patients receiving TKIs into 2 groups: those receiving a TKI in a first-line treatment setting (group B) and those receiving a TKI after prior treatment with IFN- $\alpha$ (group C). We compared each group independantly to group $\mathrm{A}$.

In Group B and Group C, we measured survival from the commencement of treatment with a TKI. We measured similar prognostic information as that measured in group $\mathrm{A}$ at the commencement of treatment with the TKI. Several patients received both sunitinib and sorafenib, and in these cases we recorded survival and baseline prognostic characteristics from commencement of treatment with the first TKI.

In all groups, we included patients who had commenced or been prescribed the specified treatment, irrespective of the duration of treatment or of their compliance to treatment or attendance at follow-up appointments.

\section{Statistical analysis}

The primary end point was OS from the commencement of treatment: IFN- $\alpha$ in group A and a TKI in both groups B 
and C. We assessed OS using the Kaplan-Meier method, and we compared treatment groups using the log rank test. We calculated hazard ratios (HRs) and 95\% confidence intervals (Cls) using a Cox proportional hazards model.

We performed several additional analyses to compensate for potential imbalances among the treatment groups. We performed a sensitivity analysis of the primary end point, excluding patients from groups $B$ and $C$ who had received treatment during a phase-III trial. We performed a subgroup analysis according to the 1999 Memorial Sloan-Kettering Cancer Center (MSKCC) prognostic model ${ }^{11}$ to enable a com- parison of prognostically matched subgroups. In this analysis we combined groups B and C for 2 reasons. First, the categorization of patients into risk groups would enable meaningful comparison of matched groups, irrespective of the treatment line in which the TKI was received. Second, combining the patients in groups $\mathrm{B}$ and $\mathrm{C}$ would enable greater power to detect any survival differences between patients treated with IFN- $\alpha$ and TKIs in each subgroup. We used the 1999 version of the MSKCC model rather than the 2001 version ${ }^{12}$ because the latter model only included patients who received IFN- $\alpha$ in a first-line treatment setting, limiting its

\begin{tabular}{|c|c|c|c|c|c|}
\hline Characteristic, \%* & $\begin{array}{l}\text { Group A, } \\
\text { IFN- } \alpha \\
n=141\end{array}$ & $\begin{array}{c}\text { Group B } \\
\text { TKI first-line, } \\
n=81\end{array}$ & $\begin{array}{l}p \text { value, } \\
\text { B v. A }\end{array}$ & $\begin{array}{c}\text { Group C } \\
\text { TKI second-line, } \\
n=53\end{array}$ & $\begin{array}{l}p \text { value, } \\
\text { C v. A }\end{array}$ \\
\hline Median age (range), yr & $57(30-81)$ & $61(39-87)$ & & $58(40-83)$ & \\
\hline \multicolumn{6}{|l|}{ Sex } \\
\hline Female & 32 & 28 & \multirow{2}{*}{0.58} & 21 & \multirow{2}{*}{0.13} \\
\hline Male & 68 & 72 & & 79 & \\
\hline \multicolumn{6}{|l|}{ Prior nephrectomy } \\
\hline Yes & 68 & 67 & \multirow[t]{2}{*}{0.83} & 89 & \multirow{2}{*}{0.004} \\
\hline No & 32 & 33 & & 11 & \\
\hline \multicolumn{6}{|l|}{$\begin{array}{l}\text { Time form diagnosis to } \\
\text { treatment }\end{array}$} \\
\hline$<12 \mathrm{mo}$ & 66 & 54 & \multirow{2}{*}{0.09} & 15 & \multirow{2}{*}{$<0.001$} \\
\hline$\geq 12 \mathrm{mo}$ & 34 & 46 & & 85 & \\
\hline \multicolumn{6}{|l|}{ Prior radiotherapy } \\
\hline Yes & 28 & 30 & \multirow{2}{*}{0.75} & 45 & \multirow{2}{*}{0.020} \\
\hline No & 72 & 70 & & 55 & \\
\hline \multicolumn{6}{|l|}{ Hemoglobin } \\
\hline Normal & 54 & 57 & \multirow{3}{*}{0.68} & 55 & \multirow{3}{*}{0.92} \\
\hline Low & 44 & 42 & & 45 & \\
\hline Unknown & 2 & 1 & & 0 & \\
\hline \multicolumn{6}{|l|}{ Corr. Ca++ } \\
\hline Normal & 55 & 73 & \multirow{3}{*}{0.01} & 81 & \multirow{3}{*}{$<0.001$} \\
\hline High & 7 & 17 & & 17 & \\
\hline Unknown & 38 & 10 & & 2 & \\
\hline \multicolumn{6}{|l|}{ LDH } \\
\hline$\leq 1.5$ ULN & 83 & 75 & \multirow{3}{*}{0.17} & 87 & \multirow{3}{*}{0.52} \\
\hline$>1.5$ ULN & 9 & 5 & & 11 & \\
\hline Unknown & 8 & 20 & & 2 & \\
\hline \multicolumn{6}{|l|}{ Karnofsky PS } \\
\hline$\geq 80$ & 57 & 75 & \multirow{2}{*}{0.01} & 58 & \multirow{2}{*}{0.83} \\
\hline$<80$ & 43 & 25 & & 42 & \\
\hline \multicolumn{6}{|l|}{ Metastatic sites } \\
\hline$\leq 1$ & 28 & 30 & \multirow{2}{*}{0.75} & 19 & \multirow{2}{*}{0.21} \\
\hline$>1$ & 72 & 70 & & 81 & \\
\hline
\end{tabular}


application to the TKI cohort, many of whom received treatment in a second-line setting. Finally, we performed univariate and multivariate analysis using the Cox proportional hazards model to identify factors influencing survival and examine the impact of treatment when controlled for these factors. We used a standard model-building method to obtain the most parsimonious model.

We assessed the impact of nephrectomy on survival with multivariate analysis using the Cox proportional hazards model. We performed a separate analysis for patients treated with TKIs (groups B and C) in addition to the analysis of the entire cohort. The presence of a nephrectomy before treatment has been found to correlate with a time between diagnosis and treatment greater than or equal to 12 months, ${ }^{11,12}$ which is assumed to be a marker of indolent disease. As our goal was to assess the therapeutic benefit of a nephrectomy in patients treated with TKIs, we included time between diagnosis and treatment as a variable in the multivariate model in addition to other prognostic variables to minimize the influence from this and other confounding variables. We defined diagnosis as the date of the first histological evidence of renal cell carcinoma (RCC), irrespective of the stage at that point in time. In many patients, the diagnosis corresponded to the initial nephrectomy, which was often performed before metastatic disease had become apparent.

\section{Results}

\section{Patients}

We included 141 patients in the IFN- $\alpha$ cohort (group A) and 134 patients in the TKI cohort; in the TKI cohort, 81 patients received their treatment as a first-line therapy (group B) and
53 received treatment after prior IFN- $\alpha$ therapy (group C). The type of TKI received was sunitinib in 97 patients, sorafenib in 17 patients and both agents in 20 patients. Eighteen patients in the TKI cohort received treatment during 1 of 2 phase-III trials: 7 in group B and 11 in group C.

Baseline characteristics are presented in Table 1. Patients in group B were similar to those in group A with the exception of a higher proportion of patients with Karnofsky performance status (KPS) greater than or equal to $80 \%$ in group $B$ versus group A (75\% v. 57\%). Group C differed from group $\mathrm{A}$ in that group $\mathrm{C}$ had a higher proportion of patients with a prior nephrectomy ( $89 \%$ v. $68 \%$ ) and a higher proportion of patients with time between diagnosis and treatment that was 12 months or longer (85\% v. 34\%). Group C also had a higher proportion of patients having received radiotherapy before treatment compared with group A (45\% v. $28 \%$ ).

Baseline hypercalcemia was more common in groups B and $C(19 \%$ and $17 \%$ of those for whom results were available) compared with group $\mathrm{A}$ ( $11 \%$ of those for whom results were available); however, baseline calcium was not available for $38 \%$ of patients in group A.

The proportion of patients in each MSKCC prognostic group is presented in Table 2. There was a higher proportion of patients with favourable risk in the TKI cohort (groups B and C) compared with the IFN- $\alpha$ cohort (group A), and a lower proportion of patients with intermediate risk in the TKI than the IFN- $\alpha$ cohort. The proportion of patients with poor risk was similar between the 2 cohorts.

\section{Survival}

The median follow-up of patients censored (alive) at the time of last follow-up was 38.3 months for group A, 14.5 months for group B and 24.9 months for group C. Treatment with a

\begin{tabular}{|c|c|c|c|c|c|}
\hline \multirow[b]{3}{*}{$\begin{array}{l}\text { MSKCC prognostic } \\
\text { group, risk }\end{array}$} & \multicolumn{5}{|c|}{ Group } \\
\hline & \multicolumn{4}{|c|}{ No. (\%) of patients } & \multirow{2}{*}{$\begin{array}{l}p \text { value } \\
\mathrm{B}+\mathrm{C} \text { v. A }\end{array}$} \\
\hline & $\begin{array}{c}\text { A, } \\
\text { IFN- } \alpha, \\
n=112\end{array}$ & $\begin{array}{c}\mathrm{B}, \\
\text { TKI first-line, } \\
n=70\end{array}$ & $\begin{array}{c}\text { C, } \\
\text { TKI second-line, } \\
n=52\end{array}$ & $\begin{array}{c}\mathrm{B}+\mathrm{C} \\
\mathrm{TKI} \\
n=122\end{array}$ & \\
\hline Favourable $†$ & $21(18.8)$ & $29(41.1)$ & 18 (34.6) & 47 (38.5) & 0.07 \\
\hline Intermediate $\neq$ & 66 (58.9) & $25(35.7)$ & 22 (42.3) & 47 (38.5) & 0.010 \\
\hline Poor£ & $25(22.3)$ & $16(22.9)$ & 12 (23.1) & 28 (22.9) & 0.25 \\
\hline \multicolumn{6}{|c|}{ 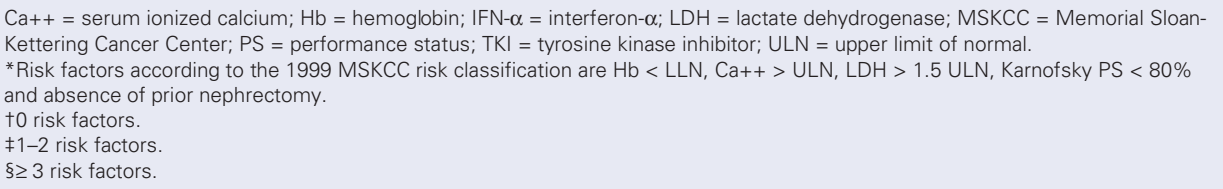 } \\
\hline
\end{tabular}


TKI was associated with improved OS, irrespective of whether the TKI was received as a first (group B) or second-line therapy (group C) (Fig. 1). The HR (and 95\% Cl) for OS in group B versus group A was $0.61(0.42-0.89), p=0.010$. The HR (and $95 \% \mathrm{Cl}$ ) for OS in group $\mathrm{C}$ versus group $\mathrm{A}$ was 0.62 (0.42-0.92), $p=0.017$. The median survival for groups $A$, $B$ and $C$ was 10 months, 15.8 months and 19.5 months, respectively.

When patients who received a TKI during a phase-III study were excluded from the analysis, $O S$ in group $C$ versus group A remained significant, (HR 0.60, 95\% Cl 0.39-0.93, $p=0.020)$; however, OS in group B versus group $\mathrm{A}$ was not significant (HR 0.72, 95\% Cl 0.48-1.06, $p=0.10$ ) (Fig. 2).

Stratification of patients into MSKCC risk groups revealed significant improvements in OS in the TKI versus the IFN$\alpha$ cohort for low- and intermediate-risk groups, with no difference observed in the poor-risk group (Table 3). Results of the univariate and multivariate analysis for the entire cohort are presented in Table 4 and Table 5, respectively. Treatment with a TKI was associated with improved OS on multivariate analysis.

\section{Impact of nephrectomy on survival}

Nephrectomy before treatment in the entire cohort of patients was associated with improved OS on univariate analysis. On multivariate analysis of the entire cohort of patients, prior nephrectomy correlated with time between diagnosis and treatment ( $\geq 12 \mathrm{mo} \mathrm{v.}<12 \mathrm{mo})$, and was not independently

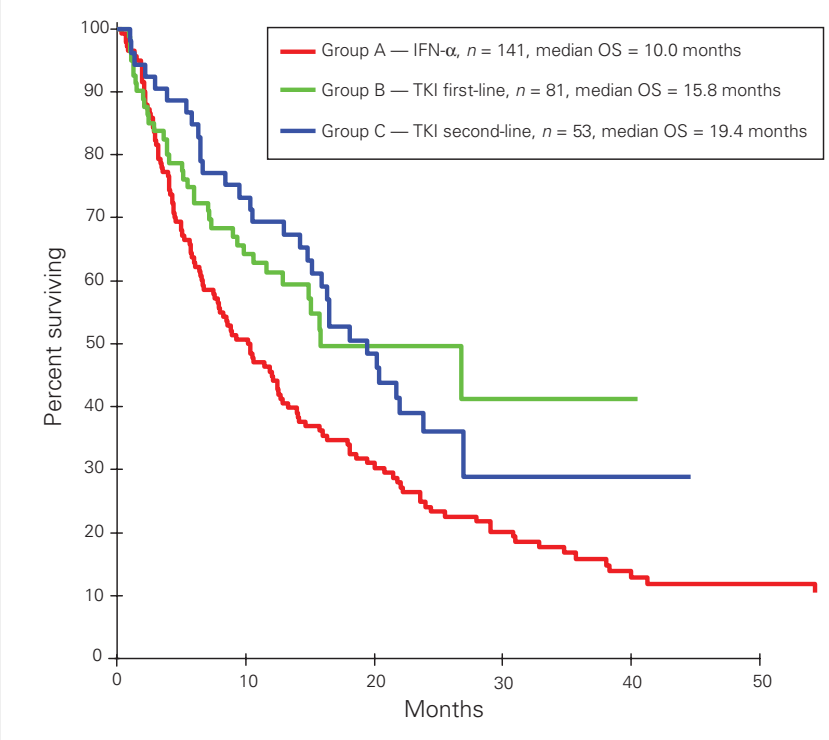

Fig. 1. Overall survival among patients treated with tyrosine kinase inhibitors (TKIs) compared with patients treated with interferon- $\alpha$ (IFN- $\alpha$ ). associated with improved survival. On multivariate analysis of the TKI cohort (groups B and C), prior nephrectomy was independently associated with improved OS (Table 6). The relation between nephrectomy, time between diagnosis and treatment and survival in the TKI cohort is illustrated in Figure 3.

\section{Discussion}

This study is important because it confirms that benefits from TKIs seen in 2 phase-III trials translate into an OS benefit in a "real-world" setting. Patients eligible for clinical trials are selected for good performance status and lack of comorbidities and therefore do not always represent the overall population in whom the results of such trials will be applied. Consequently results do not always have external validity to patients treated in routine practice..$^{13}$ Our study included every patient who commenced a TKI for mRCC in Alberta over a 3.5-year period. Although 18 patients received a TKI as part of a phase-III study, all other patients were effectively treated "offstudy" insofar as there were no patients treated during this time who failed to qualify for a TKI on expanded access or compassionate access programs. Although the OS benefit of group B compared with group A lost statistical significance when we excluded 7 patients from group B who had received their TKIs in a phase-III trial, there nonetheless remained a favourable trend for improved OS with a HR of $0.72, p=0.09$.

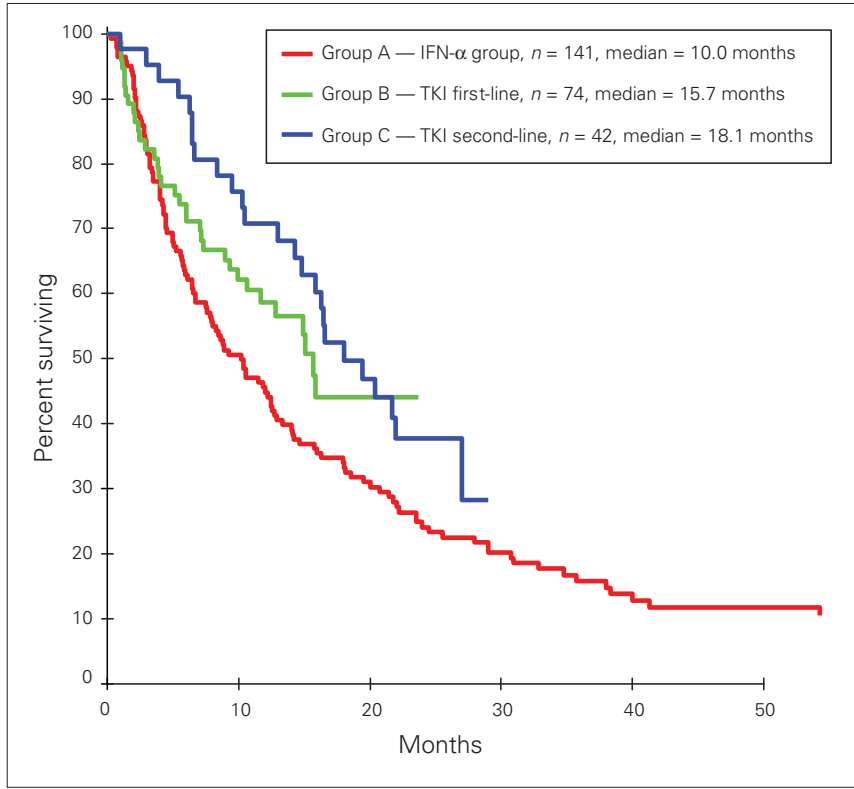

Fig. 2. Overall survival among patients treated with tyrosine kinase inhibitors (TKIs) compared with patients treated with interferon- $\alpha$ (IFN- $\alpha$ ), excluding patients who received TKIs as part of a phase-III trial. 
Warren et al.

The median OS of both the IFN- $\alpha$ cohort $(10 \mathrm{mo}$ ) and TKI cohort (15.8 mo in group B, 19.5 mo in group C) was less than that recently reported by Figlin and colleagues ${ }^{9}$ for IFN- $\alpha$ (21.8 mo) and sunitinib (26.4 mo). One explanation is the less stringent selection criteria used in treating patients in routine practice compared with a clinical trial. For instance, in our study 6 patients had brain metastases when commenc- ing their TKIs; these patients would have been excluded in the trial reported by Figlin and colleagues. Several other baseline characteristics favouring their study compared with ours include the proportion of patients with a prior nephrectomy $(90 \%$ v. $72 \%)$, the proportion of patients classified into the poor-risk subgroup $(6.5 \% \mathrm{v} .23 \%)$ and the proportion of patients having received prior radiotherapy (14\% v. $32 \%)$.

Table 3. Survival according to Memorial Sloan-Kettering Cancer Center prognostic subgroup

\begin{tabular}{|c|c|c|c|c|}
\hline \multirow{2}{*}{$\begin{array}{l}\text { MSCKK prognostic } \\
\text { subgroup, risk }\end{array}$} & \multicolumn{2}{|c|}{ Group, median survival, mo } & \multirow[b]{2}{*}{$\mathrm{HR}(95 \% \mathrm{Cl})$} & \multirow[b]{2}{*}{$p$ value } \\
\hline & A, IFN- $\alpha$ & $\mathrm{B}+\mathrm{C}, \mathrm{TKI}$ & & \\
\hline Favourable & 22 & NR & $0.36(0.15-0.85)$ & 0.019 \\
\hline Intermediate & 11 & 16 & $0.60(0.38-0.96)$ & 0.032 \\
\hline Poor & 3 & 4 & $0.81 \quad(0.46-1.42)$ & 0.46 \\
\hline
\end{tabular}

Table 4. Univariate analysis of variables associated with improved survival for entire cohort (groups A, B and C)

\begin{tabular}{|c|c|c|}
\hline Variable & $\mathrm{HR}(95 \% \mathrm{CI})$ & $p$ value \\
\hline Age, yr $<60 v . \geq 60$ & $1.06(0.79-1.41)$ & 0.70 \\
\hline Sex, female v. male & $1.67(1.23-2.26)$ & $<0.001$ \\
\hline Prior nephrectomy, yes v. no & $0.42(0.31-0.57)$ & $<0.001$ \\
\hline $\begin{array}{l}\text { Time from diagnosis to treatment, } \\
\mathrm{mo}<12 \mathrm{v} . \geq 12\end{array}$ & $0.48(0.36-0.64)$ & $<0.001$ \\
\hline Prior radiotherapy, yes v. no & $0.68(0.50-0.92)$ & 0.012 \\
\hline Metastatic sites, $\leq 1$ v. $>1$ & $0.67(0.48-0.93)$ & 0.018 \\
\hline Corr $\mathrm{Ca}++$, normal v. high & $0.49(0.32-0.74)$ & $<0.001$ \\
\hline Hemoglobin, normal v. low & $0.41(0.30-0.55)$ & $<0.001$ \\
\hline $\mathrm{LDH}_{1} \leq 1.5$ v. $>1.5 \mathrm{ULN}$ & $0.30(0.19-0.47)$ & $<0.001$ \\
\hline Karnofsy PS, $\geq 80 \%$ v. $<80 \%$ & $0.34(0.25-0.46)$ & $<0.001$ \\
\hline Treatment, TKI v. IFN- $\alpha$ & $0.61(0.45-0.83)$ & 0.002 \\
\hline
\end{tabular}

Table 5. Multivariate analysis* of variables associated with improved survival for entire cohort (groups A, B and C)

\begin{tabular}{|c|c|c|}
\hline Variable & HR $(95 \% \mathrm{Cl})$ & $p$ value \\
\hline $\begin{array}{l}\text { Time from diagnosis to treatment, } \\
\mathrm{mo}<12 \mathrm{v} . \geq 12\end{array}$ & $0.51(0.37-0.72)$ & $<0.001$ \\
\hline Metastatic sites, $\leq 1 \mathrm{v} .>1$ & $0.62(0.43-0.90)$ & 0.013 \\
\hline Hemoglobin, normal v. low & $0.61(0.44-0.85)$ & 0.003 \\
\hline $\mathrm{LDH}, \leq 1.5 \mathrm{v} .>1.5 \mathrm{ULN}$ & $0.33(0.20-0.54)$ & $<0.001$ \\
\hline Karnofsy PS, $\geq 80 \%$ v. $<80 \%$ & $0.44(0.32-0.61)$ & $<0.001$ \\
\hline Treatment, TKI v. IFN- $\alpha$ & $0.69(0.49-0.98)$ & 0.036 \\
\hline
\end{tabular}


One baseline characteristic that favoured our study compared with that of Figlin and colleagues was the proportion of patients with 1 or no sites of disease $(27 \%$ v. $17 \%)$.

Retrospective studies are prone to bias, and in our study there were several baseline characteristics that favoured the TKI groups. Group B consisted of a higher proportion of patients with a KFS of $80 \%$ or greater compared with group A. A higher proportion of patients in group $\mathrm{C}$ had undergone a nephrectomy before treatment and had a time between diagnosis and treatment of 12 months or longer compared with group A. This may reflect indolent disease biology of patients who are well enough to receive treatment in a second-line setting. Interestingly, a higher proportion of patients in group $\mathrm{C}$ had received prior radiotherapy, which is associated with inferior survival in 1 published series, ${ }^{14}$ compared with group A.

We performed several additional analyses to compensate for imbalances in baseline characteristics. We performed multivariate analysis to assess the impact of treatment adjusting for known prognostic variables. In this analysis, treatment with a TKI was associated with improved OS compared with IFN- $\alpha$, suggesting a real benefit from TKIs. Another method we used to adjust for baseline treatment imbalances was to incorporate subgroup analysis based on the MSKCC risk groups. Although a higher proportion of patients treated with TKIs had a favourable MSKCC prognostic score at baseline (relative to the IFN- $\alpha$ group) with a corresponding lower proportion of patients in the intermediate-risk group, in both these subgroups OS was superior in the TKI versus the IFN- $\alpha$ cohort. A similar proportion of patients in each treatment cohort were categorized into the poor-risk subgroup. In our study there was no survival benefit seen with TKIs compared with IFN- $\alpha$ in this subgroup; however, the small number of patients (53) in the poor-risk group may have lead to this study being underpowered to identify a benefit of TKIs in this group. This is a subgroup that is under-represented in

\begin{tabular}{|c|c|c|}
\hline Variable & $\mathrm{HR}(95 \% \mathrm{Cl})$ & $p$ value \\
\hline Prior nephrectomy, yes v. no & $0.38(0.19-0.74)$ & 0.005 \\
\hline Time from diagnosis to $R x, m o<12 v . \geq 12$ & $0.62(0.33-1.09)$ & 0.15 \\
\hline Corr $\mathrm{Ca}++$, normal v. high & $0.43(0.23-0.81)$ & 0.008 \\
\hline Hemoglobin, normal v. low & $0.57(0.33-0.98)$ & 0.004 \\
\hline $\mathrm{LDH}, \leq 1.5 \mathrm{v} .>1.5 \mathrm{ULN}$ & $0.34(0.15-0.77)$ & $<0.001$ \\
\hline Karnofsy PS, $\geq 80 \%$ v. $<80 \%$ & $0.46(0.26-0.83)$ & $<0.001$ \\
\hline \multicolumn{3}{|c|}{$\begin{array}{l}\mathrm{Cl}=\text { confidence interval; } \text { Corr } \mathrm{Ca}++=\text { corrected serum ionized calcium; } \mathrm{HR}=\text { hazard ratio; } \mathrm{LDH}=\text { lactate dehydrogenase; } \\
\mathrm{PS}=\text { performance status; } \mathrm{ULN}=\text { upper limit of normal. } \\
{ }^{*} \text { Groups standard model building strategy used for analysis. }\end{array}$} \\
\hline
\end{tabular}
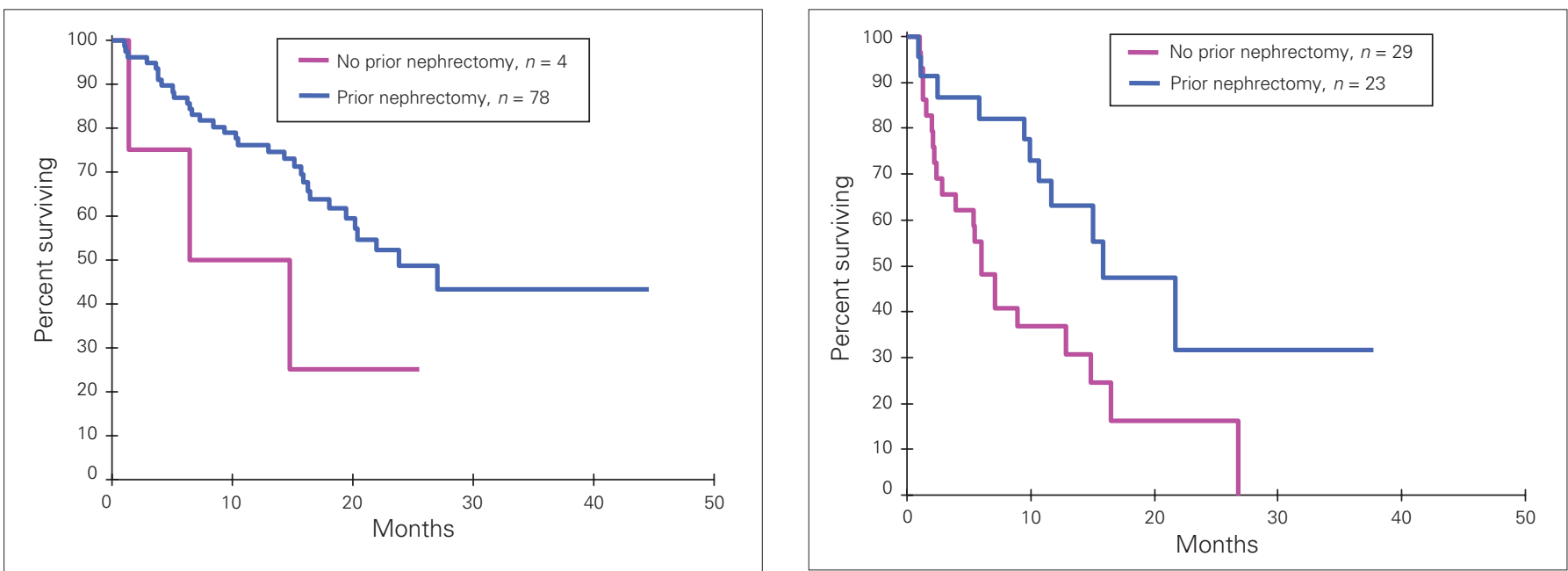

Fig. 3. Overall survival among patients treated with a tyrosine kinase inhibitor who had a prior nephrectomy compared with those who did not. (Left) Patients for whom time between diagnosis and treatment was greater than or equal to 12 months. (Right) Patients for whom time between diagnosis and treatment was less than 12 months. 
clinical trials and for whom the benefits of TKIs are not clear. In a similarly designed retrospective study performed in British Columbia, sunitinib improved OS compared with IFN- $\alpha$ in this subgroup. ${ }^{15}$

Although additional analyses could be performed to adjust for known prognostic differences between treatment groups, there may have been bias for which adjustments could not be made. The long accrual period (>10 yr) combined with the IFN- $\alpha$ cohort being a historic rather than a contemporary control group, means that patients treated with TKIs may have reaped the benefits of advances in medical technology, supportive care and oncology practice. For instance, improvements in medical imaging may have lead to earlier detection of metastatic disease in the TKI cohort. Theoretically this could result in lead time bias, where treatment is started earlier in the disease course, leading to an apparent increase in survival. Another advancement made during the accrual period was that of temsirolimus, a mammalian target of rapamycin (mTOR) inhibitor, which demonstrated efficacy in the first-line treatment of patients with poor prognoses. ${ }^{16}$ Four patients treated with TKIs received temsirolimus after progression. This was not available to the IFN- $\alpha$ cohort. Recognizing these limitations, we believe our study compliments the existing evidence in favour of TKIs and does not function as standalone evidence of their efficacy.

We did not assess the difference between sunitinib and sorafenib in our study, and we included patients treated with either of these medications in the TKI group. Broadly, the mechanism of action of each agent is similar, and although there are differences in the molecular profile of each drug, it is not known whether this alters the clinical benefit of each agent. ${ }^{17}$ Currently there are no trials that have compared the efficacy of sunitinib versus that of sorafenib in $\mathrm{mRCC}$.

The final end point we examined was the impact of nephrectomy on survival in mRCC. The clinical implication concerns the question as to whether patients presenting with mRCC should undergo a cytoreductive nephrectomy before starting a TKI. It is difficult to assess the therapeutic value of a nephrectomy in a retrospective series because of confounding variables associated with having or not having had a nephretomy before treatment for metastatic disease. One reason why a patient may not have had a prior nephrectomy is that they presented with metastatic disease and proceeded directly to systemic treatment. This would potentially correlate with more aggressive disease biology and inferior survival. In an attempt to adjust for this confounding variable, we included in the multivariate model times between diagnosis and treatment of 12 months or more or less than 12 months. Another reason why patients may not have had a prior nephrectomy is that they were considered poor surgical candidates because of poor performance status or medical comorbidities. It was beyond the scope of our study to include variables related to fitness for surgery in the multivariate model.

In the multivariate analysis, nephrectomy was independently associated with improved OS for the TKI cohort (groups $B$ and $C$ ), but not for the combined population (groups A, B and C). This would seem to contradict the results of 2 randomized trials that demonstrated a benefit of cytoreductive nephrectomy before IFN- $\alpha$ in patients presenting with metastatic disease..$^{3-5}$ Although the reasons for a lack of benefit of nephrectomy in patients treated with IFN- $\alpha$ in our series are not entirely clear, it is possible that the number of patients in our study was insufficient to detect a small improvement in OS from nephrectomy. Similarly, the reasons for a seemingly greater benefit of nephrectomy in the TKI cohort are not clear. It may reflect a chance finding, or perhaps nephrectomy has a greater therapeutic benefit in patients treated with TKIs than those treated with IFN- $\alpha$. These results are hypothesis-generating and we await the results of prospective studies. Until these become available, we believe that a therapeutic nephrectomy may have value in patients who are good surgical candidates with a low metastatic burden.

\section{Conclusion}

Tyrosine kinase inhibitors are a major breakthrough in the management of $\mathrm{mRCC}$ and offer new hope to patients being treated for this cancer. Based on our study it is evident that TKIs are effective agents in the treatment of mRCC and should be incorporated into all first-line treatment strategies. The benefit of a cytoreductive nephrectomy in the presence of metastatic disease may be of value, but needs to be established in randomized clinical trials.

From the ${ }^{*}$ Cross Cancer Institute and the †Department of Oncology, ${ }^{\ddagger}$ University of Alberta, Edmonton, Alta., the §Department of Medicine, Tom Baker Cancer Centre, and the IFaculty of Kinesiology and Department of Medical Sciences, University of Calgary, Calgary, Alta.

This article has been peer reviewed.

Competing interests: None declared.

\section{References}

1. Canadian cancer statistics. Toronto: Canadian Cancer Society, National Cancer Institute of Canada; 2007.

2. Coppin C, Porzsolt F, Awa A, et al. Immunotherapy for advanced renal cell cancer. Cochrane Database Syst Rev 2005;CD001425.

3. Flanigan RC, Salmon SE, Blumenstein EA. Nephrectomy followed by interferon alfa-2B compared with inteferon alfa-2B alone for metastatic renal-cell cancer. N Engl J Med 2001;345:1655-9.

4. Mickisch GH, Garin A, van Poppel H, et al. RS Radical nephrectomy plus interferon-alpha-based immunotherapy 
compared with interferon alpha alone in metastatic renal-cell carcinoma: a randomized trial. Lancet 2001;358:966-70.

5. Flanigan RC, Mickisch GH, Sylvester R. Cytoreductive nephrectomy in patients with metastatic renal cancer: a combined analysis. J Urol 2004;171:1071-6.

6. Garcia JA, Rini BI. Recent progress in the management of advanced renal cell carcinoma. CA Cancer J Clin 2007:57:112-25

7. Motzer RJ, Hutson TE, Tomczak $P$, et al. Sunitinib versus interferon alfa in metastatic renal-cell carcinoma. N Engl J Med 2007;356:115-24

8. Escudier B, Eisen T, Stadler WM, et al. Sorafenib in advanced clear-cell renal-cell carcinoma. N Engl J Med 2007;356:125-34.

9. Figlin RA, Hutson TE, Tomczak P, et al. Overall survival with sunitinib versus Interferon (IFN)-alfa as firstline treatment of metastatic renal cell carcinoma (mRCC). J Clin Oncol 2008;26:5024. [abstract].

10. Population by year, by province and territory. Ottawa: Statistics Canada; 2008. Available: www40.statcan.gc.ca/101/cst01/dem002a-eng.htm (accessed 2009 July 14).

11. Motzer RJ, Mazumdar M, Bacik J, et al. Survival and prognostic stratification of 670 patients with advanced renal cell carcinoma. J Clin Oncol 1999;17:2530-40.

12. Motzer RJ, Bacik J, Murphy BA, et al. Interferon-alfa as a comparative treatment for clinical trials of new therapies against advanced renal cell carcinoma. J Clin Oncol 2002;20:289-96.

13. Rothwell PM. External validity of randomised controlled trials: "To whom do the results of this trial apply?" Lancet 2005;365:82-93.

14. Mekhail TM, Abou-Jawde RM, Boumerhi G, et al. Validation and extension of the Memorial Sloan-Kettering prognostic factors model for survival in patients with previously untreated metastatic renal cell carcinoma. J Clin Oncol 2005;23:832-41.

15. Heng DY, Chi KN, Murray N, et al. A population-based study evaluating the impact of sunitinib on overall survival in the treatment of patients with metastatic renal cell carcinoma (mRCC); 2008 Feb 14-16; San Francisco. Genitourinary Cancers Symposium: Abstract 395; 2008.

16. Hudes $G$, Carducci $M$, Tomczak $P$, et al. Temsirolimus, interferon alfa, or both for advanced renal-cell carcinoma. N Engl J Med 2007;356:2271-81.

17. Stein MN, Flaherry KT. CCR drug updates: sorafenib and sunitinib in renal cell carcinoma. Clin Cancer Res 2007; $13: 3765-70$

Correspondence: Dr. Mark Warren, Cross Cancer Institute, University of Alberta, 11560 University Ave., Edmonton AB T6G 1Z2; markandnaomi2@bigpond.com

\section{Correction}

Please note the following corrections to the references of the Canadian Kidney Cancer Forum 2009. ${ }^{1}$ The original reference 28 on page 202 should be replaced with following 2 references:

- Rini Bl, Halabi S, Rosenberg JE, et al. Bevacizumab plus interferon alfa compared with interferon alfa monotherapy in patients with metastatic renal cell carcinoma: CALGB 90206. J Clin Oncol 2008;26:5422-8

- Escudier B, Pluzanska A, Koralewski P, et al. Bevacizumab plus interferon alfa-2a for treatment of metastatic renal cell carcinoma: a randomized, double-blind phase III trial. Lancet 2007;370:2103-11.

The reference 28 listed on page 203 is the correct reference.

Also, please note that $\mathrm{S}$. Hotte should have been included in the list of presenters.

\section{Reference}

1. Canadian Kidney Cancer Forum 2009. Management of kidney cancer: Canadian Kidney Cancer Forum Consensus Update. Can Urol Assoc J 2009;3:200-4. 